\title{
Characteristics and 1-Year Prognosis of Medically Treated Patients With Chronic Heart Failure in Japan - Chronic Heart Failure Analysis Registry in Tohoku District (CHART)
}

\author{
Yoshito Koseki, MD; Jun Watanabe, MD; Tsuyoshi Shinozaki, MD; Masahito Sakuma, MD; \\ Tatsuya Komaru, MD; Mitsumasa Fukuchi, MD; Masahito Miura, MD; Akihiko Karibe, MD; \\ Yuji Kon-no, MD; Hirotaka Numaguchi, MD; Mototsugu Ninomiya, MD; \\ Yutaka Kagaya, MD; Kunio Shirato, MD; the CHART Investigators
}

\begin{abstract}
The study was designed to characterize patients with chronic heart failure (CHF) in Japan in terms of the etiologies and prognosis. CHF was defined by ejection fraction ( $\mathrm{EF} \geq 50 \%$ ), left ventricular diastolic dimension (LVDD $\geq 55 \mathrm{~mm}$ ) or a past history of congestive heart failure. Among the 721 recruited patients, the most frequent etiology for CHF was dilated cardiomyopathy (DCM) in patients aged less than 59 years, and valvular heart disease (VHD) in those aged 70 years or more. The 1-year crude mortality was $8 \%$ overall and $12 \%$ in patients with myocardial infarction (MI). Sudden death accounted for $40 \%$ of the total deaths among all patients, and $60 \%$ in patients with MI. Multivariate logistic regression analysis showed that brain natriuretic peptide (BNP) was a consistent prognostic marker in CHF patients with a variety of etiologies. Total death and hospitalization because of heart failure were significantly less frequent in patients with BNP less than $100 \mathrm{pg} / \mathrm{ml}$. In conclusion, the etiologies of Japanese CHF appear to be more diverse than those of other Western countries, but BNP is an excellent prognostic marker despite the etiological diversity. Sudden, unexpected death in CHF patients is also a serious problem in Japan. A nation-wide epidemiologic study should be done to characterize Japanese CHF. (Circ J 2003; 67: 431-436)
\end{abstract}

Key Words: Brain natriuretic peptide; Ejection fraction; Etiology; Heart failure death; Sudden death

$\mathbf{N}$ umerous randomized controlled trials (RCT) have been performed in Europe and the United States to assess the treatment of chronic heart failure $(\mathrm{CHF})^{1-3}$ but it is generally recognized that the underlying heart diseases and the prognosis of CHF in Japan differ from those in Europe and the US, although only a few reports address this issue.,5 In particular, the actual status of sudden death among patients with CHF, which is a major problem in Europe and the US, 6,7 has not been systematically investigated in Japan. It therefore remains questionable whether the available RCT-based evidence can be applied to the Japanese situation.

The present study was designed to characterize Japanese patients with CHF treated by a physician in charge. We investigated the etiology and the prognosis of CHF, especially focusing on sudden death. In addition, we evaluated the predictive values of prognostic markers, including echocardiographic measurements and brain natriuretic peptide (BNP). To investigate these issues, we established a study group for the registry of patients with CHF in Tohoku-district, which is the northeast territory of Honshu-Island in Japan.

(Received September 12, 2002; revised manuscript received February 10, 2003; accepted February 20, 2003)

Tohoku University Graduate School of Medicine, Department of Cardiovascular Medicine, Sendai, Japan

Mailing address: Kunio Shirato, MD, Tohoku University Graduate School of Medicine, Department of Cardiovascular Medicine, 1-1 Seiryo-Machi Aoba-Ku, Sendai 980-8574, Japan. E-mail: shirato@ int1.med.tohoku.ac.jp

\section{Methods}

Source of Patients' Data

The chronic heart failure analysis registry in Tohoku district (CHART) was established in February 2000 and included 21 hospitals in which well-trained physicians were in charge of the CHF patients. Patients 20 years or older with the following clinical findings of heart failure were eligible for registration.

(1) Echocardiographic ejection fraction (EF): $\geq 50 \%$.

(2) Echocardiographic left ventricular end-diastolic dimension (LVDD): $\geq 55 \mathrm{~mm}$.

(3) The patient had certain organic heart diseases and a documented history of clinical congestive heart failure.

The CHART investigators registered the patients who had been in a stable condition for more than 3 weeks and met at least one of the 3 criteria. The present study used a multicenter prospective observational approach that did not interfere with the treatment of individual patients with CHF and was approved by the ethics committee.

Diagnosis of the underlying heart disease was performed primarily by the physician in charge according to contemporary standards. We classified the etiologies into 6 groups: dilated cardiomyopathy (DCM), myocardial infarction (MI), valvular heart disease (VHD), left ventricular hypertrophy (LVH), congenital heart diseases (CHD), and unclassified heart diseases. The DCM group included both primary and secondary myopathies, but not so called 'ischemic cardiomyopathy', and also included patients with left ven- 
Table 1 Basic Data of the Patients With Chronic Heart Failure (CHF)

\begin{tabular}{|c|c|c|c|c|c|c|c|}
\hline & $\begin{array}{c}\text { Dilated } \\
\text { cardiomyopathy }\end{array}$ & $\begin{array}{l}\text { Myocardial } \\
\text { infarction }\end{array}$ & $\begin{array}{c}\text { Valvular } \\
\text { heart disease }\end{array}$ & $\begin{array}{l}\text { Left ventricular } \\
\text { hypertrophy }\end{array}$ & $\begin{array}{l}\text { Congential } \\
\text { heart disease }\end{array}$ & Unclassified & $\begin{array}{l}\text { Total no. } \\
\text { of patients }\end{array}$ \\
\hline No of cases (\%) & 194 (27) & $163(23)$ & $245(34)$ & $100(14)$ & $10(1)$ & $9(1)$ & 721 \\
\hline Female/Male & $53 / 141$ & $40 / 123 * 1$ & $97 / 148$ & $37 / 63$ & $5 / 5$ & $5 / 4$ & $237 / 484$ \\
\hline Mean age (SD) & $82(14) * 2$ & $70(10)$ & $72(11)$ & $71(14)$ & $72(6)$ & $74(8)$ & $69(11)$ \\
\hline$L V D D(S D)$ & $60(9) * 3$ & $59(9) * 3$ & $55(9)$ & $50(9)$ & $50(13)$ & $54(6)$ & - \\
\hline$E F \%(S D)$ & $38(12) * 4$ & $39(12) * 4$ & $51(14)$ & $55(15)$ & $49(16)$ & $50(9)$ & - \\
\hline$B N P \mathrm{pg} / \mathrm{ml}$ & $226(419)$ & 305 (389) & $216(302)$ & $280(304)$ & $383(305)$ & $133(125)$ & - \\
\hline $\operatorname{ACEI}(\%)$ & 72 & 58 & 51 & 60 & 50 & 22 & - \\
\hline$A R B(\%)$ & 13 & 4 & 5 & 9 & 10 & 22 & - \\
\hline$\beta$-blocker (\%) & 41 & 18 & 5 & 15 & 10 & 0 & - \\
\hline Digitals $(\%)$ & 55 & 26 & 64 & 46 & 70 & 55 & - \\
\hline Diuretions (\%) & 80 & 78 & 86 & 75 & 100 & 65 & - \\
\hline
\end{tabular}

$L V D D$, left ventricular diastolic dimension; EF, ejection fraction; BNP, brain natriuretic peptide; ACEI, angiotensin-converting enzyme inhibitors; ARB, angiotensin II receptor blockers.

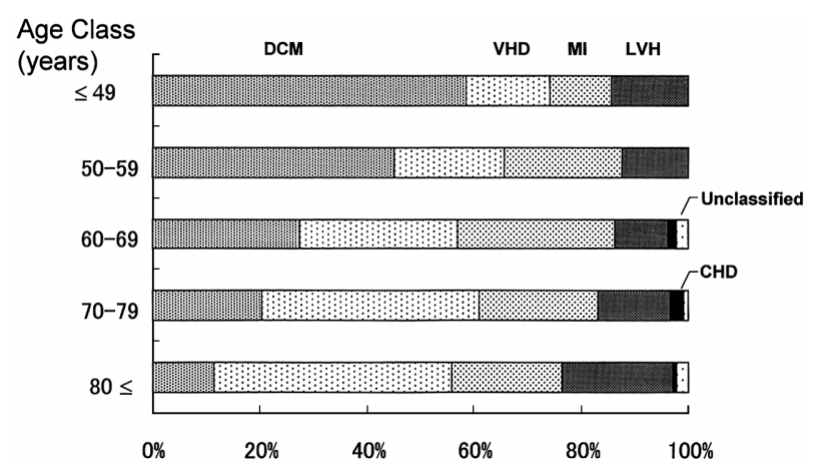

Fig 1. Distributions of the underlying heart diseases according to age class. DCM is most frequent in patients $\geq 59$ years old, and VHD is most frequent in patients $>70$ years old. DCM includes secondary dilated cardiomyopathy but not 'ischemic cardiomyopathy'. MI included 'ischemic cardiomyopathy'. Abbreviations, see text.

tricular (LV) pump failure, but excluded ischemic heart disease, severe valvular heart disease, systemic hypertension, and cor pulmonale. When the patients with CHF had a documented history of MI and/or typical findings of MI on ECG and echocardiography, they were placed in the MI group, which also included 'ischemic cardiomyopathy'. VHD was determined mainly by past history (rheumatic fever and/or the long-lasting heart murmur), physical examination, and echocardiographic findings of mitral and/or aortic valve disorders; the VHD group included patients who had undergone surgical repair. The LVH group included hypertensive heart disease and hypertrophic cardiomyopathy. Hypertensive heart disease was established by medical documentation of long-lasting hypertension and concentric left ventricular hypertrophy in which the LV wall thickness in the interventricular septum and/or posterior wall was more than $11 \mathrm{~mm}$. Hypertrophic cardiomyopathy was diagnosed by LV hypertrophy without an obvious cause. CHD was diagnosed by echocardiography and/or a cardiac catheterization; the CHD group included patients who had undergone surgical repair.

Echocardiographic measurements had to be recorded within 3 weeks before or after registration. LVDD and left ventricular end-systolic dimension were measured, and $\mathrm{EF}$ was calculated by the method of Teichholz. A BNP measurement was recommended at registration. The physician in charge assessed the New York Heart Association (NYHA) functional classification and co-morbidity accord- ing to the present status and medical findings.

\section{Data Analysis}

The study office collected the registration forms and constructed the database. The physician principally in charge performed regular follow-ups. Death from any cause and hospitalization because of exacerbation of heart failure were reported. The causes of death were categorized as exacerbation of heart failure (HF death), sudden death, and other causes. Sudden death was defined as unexpected, sudden death without recognizable cause. Death during sleep was also categorized as sudden death if it was unexpected and no particular cause of death was recognizable. Sudden death also included adequate discharge of an implantable cardioverter defibrillator.

The prognosis of patients with CHF was evaluated by Kaplan-Meier survival curve analysis and log-rank test. The start point was at registration with the study. The primary end-point was death from any cause, and the secondary end-point was death from any cause or hospitalization from worsening heart failure (HF hospitalization). The follow-up was censored once at 12 months from registration. The comparison of the incidence of events between the groups was performed by the chi-squared test. Differences in mean values were tested by analysis of variance (one-way) and Bonferroni's method. Multivariate logistic regression analysis was performed to evaluate factors affecting the 1-year prognosis: age, NYHA class, past history of congestive heart failure, LVDD, EF, BNP, diabetes mellitus (DM), hyperlipidemia (HL), and medication $\beta$ blockers, angiotensin-converting enzyme inhibitor, digitalis, and diuretics). The logistic regression analysis was computed using StatView5.0 (SAS, Cary, NC, USA).

\section{Results}

\section{Clinical Characteristics of Patients With CHF at Registration}

From February 2000 to October 2001, 868 registration forms were accepted and these patients were temporally evaluated in February 2002. We analyzed 721 patients who had events within 12 months from registration or who were followed up for more than 12 months at the time of evaluation. Among these 721 patients, 332 patients had both EF $\geq 50 \%$ and LVDD $\geq 55 \mathrm{~mm}, 130$ patients had $\mathrm{EF} \geq 50 \%$ and LVDD $<55 \mathrm{~mm}, 108$ patients had $\mathrm{EF}>50 \%$ and LVDD $\geq 55 \mathrm{~mm}$, and 151 patients, who had EF $>50 \%$ and LVDD 


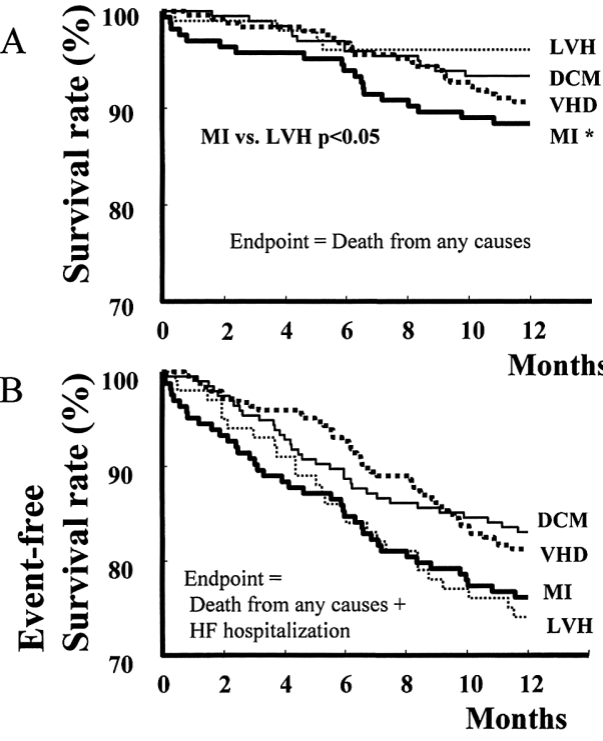

Fig 2. Kaplan-Meier survival curves. (Panel A) Survival curves in which the end-point was death from any cause. The survival rate was significantly lower in CHF patients with MI than in patients with LVH (log-rank test, $\mathrm{p}<0.05$ ). (Panel B) Event-free survival curves in which the end-points were death from any cause and HF hospitalization. Event incidences tended to be high in patients with MI and LVH, although no significant difference was found. Abbreviations, see text.

$<55 \mathrm{~mm}$, were included in the study because of their past history of unquestionable heart failure. Table 1 summarizes the basic data. VHD was the most frequent etiology in this study; the VHD group $(n=245)$ included 14 patients with aortic stenosis, 67 with aortic regurgitation, 10 with mitral stenosis, 81 with mitral regurgitation, 5 with tricuspid regurgitation, 49 with combined valvular disesase, and 19 with unspecified valvular disease. The age distribution was dependent on the underlying heart disease. The mean age of DCM patients was significantly lower than those of the MI, VHD and LVH patients (Fig 1). DCM was the most frequent etiology in patients aged 59 years or younger, and VHD was the most frequent in patients aged 70 years or older. The LVDD of the DCM and MI patients was significantly greater than that of the VHD and LVH patients, and the EF was significantly lower in DCM and MI patients compared with VHD and LVH patients. No significant differences were found in the values of BNP. Medical therapy for $\mathrm{CHF}$ is also summarized in Table 1.

\section{One-Year Prognosis of Patients With CHF}

Fig 2A shows the Kaplan-Meier survival curve for each

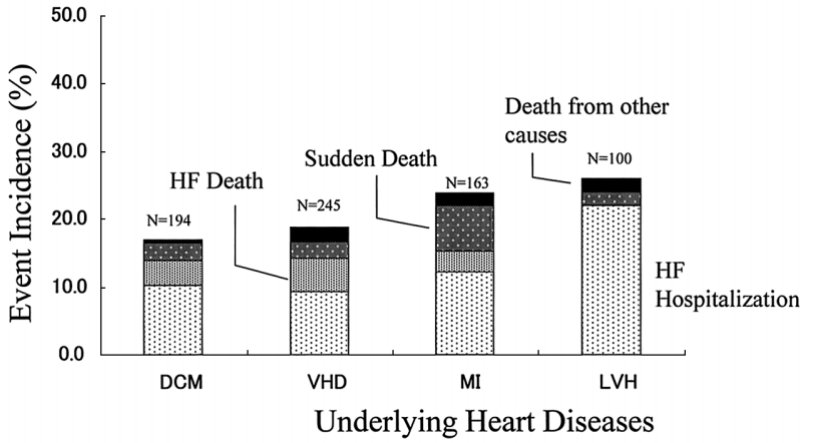

Fig 3. Summary of the event incidences for the various heart diseases. The 1-year event incidences vary from $16 \%$ (DCM) to $26 \%$ (LVH). Sudden death accounts for approximately $60 \%$ of all death in MI patients, $50 \%$ in LVH patients, $40 \%$ in DCM patients and $25 \%$ in VHD patients. Abbreviations, see text.

etiology. Death from all causes is the primary end-point. CHF patients with CHD and unclassified heart diseases were not analyzed in terms of the prognosis because numbers of cases were too small. The 1-year mortality of MI patients was significantly worse than that of $\mathrm{LVH}$ patients. No significant difference was found between the other combinations. The overall 1-year crude mortality for all patients was 8\%: $4 \%$ in $\mathrm{LVH}$ patients, $7 \%$ in DCM patients, $9 \%$ in VHD patients, and $12 \%$ in MI patients. Fig 2B shows the event-free survival curves, that is, the end-point was death from any cause or HF hospitalization. There was no significant difference in the event-free survival curves between the 4 groups. Fig 3 summarizes the events during the follow-up period. The 1-year event incidences varied from $16 \%$ (DCM) to $26 \%$ (LVH). Sudden death accounted for approximately $60 \%$ of total death in MI patients, $50 \%$ in LVH patients, $40 \%$ in DCM patients and $25 \%$ in VHD patients.

Table 2 summarizes the results of the multivariate logistic analysis. We evaluated covariates-adjusted odds ratio (OR) and the 95\% confidence interval for the 1-year incidence of events including all deaths and HF hospitalization. Only selected covariates are presented. Increased NYHA function class showed high OR in LVH patients, but was statistically insignificant $(\mathrm{p}=0.083)$. Older age was not a significant predictor in any heart disease group. Enlarged LVDD was a significant predictor in DCM patients, and EF was a significant predictor in VHD patients. BNP was a significant predictor in all groups. DM is a strong predictor in MI patients. All other covariates were statistically in significant and are not presented.

Fig 4 shows the incidence of events in patients catego-

Table 2 Adjusted Odds Ratio (OR) and 95\% Confidence Interval (95\% CI) for 1-Year Even-Incidence (All Death and HF Hospitalization)

\begin{tabular}{|c|c|c|c|c|c|c|c|c|}
\hline & \multicolumn{2}{|c|}{$D C M$} & \multicolumn{2}{|r|}{ MI } & \multicolumn{2}{|c|}{$V H D$} & \multicolumn{2}{|c|}{$L V H$} \\
\hline & $O R$ & $95 \% C I$ & $O R$ & $95 \% C I$ & OR & $95 \% C I$ & OR & $95 \% C I$ \\
\hline NYHA (/1 steps) & \multicolumn{2}{|c|}{$1.22(0.47-3.17)$} & \multicolumn{2}{|c|}{$1.21(0.51-2.86)$} & \multicolumn{2}{|c|}{$2.03(0.98-4.18)$} & \multicolumn{2}{|c|}{$6.14(0.79-47.86)$} \\
\hline Age (/10 years) & \multicolumn{2}{|c|}{$1.24(0.79-1.94)$} & \multicolumn{2}{|c|}{$1.44(0.79-2.65)$} & \multicolumn{2}{|c|}{$1.61(0.97-2.70)$} & \multicolumn{2}{|c|}{$0.69(0.25-1.46)$} \\
\hline$L V D D(/ 5 \mathrm{~mm})$ & \multicolumn{2}{|c|}{$1.46(1.04-2.05)$} & \multicolumn{2}{|c|}{$1.07(0.73-1.58)$} & \multicolumn{2}{|c|}{$0.79(0.60-1.03)$} & \multicolumn{2}{|c|}{$1.44(0.64-3.21)$} \\
\hline$E F(/ 5 \%)$ & \multicolumn{2}{|c|}{$1.08(0.80-1.46)$} & \multicolumn{2}{|c|}{$0.96(0.74-1.24)$} & \multicolumn{2}{|c|}{$0.77(0.63-0.93)$} & \multicolumn{2}{|c|}{$0.77(0.54-1.09)$} \\
\hline$B N P(/ 50 \mathrm{pg} / \mathrm{m})$ & \multicolumn{2}{|c|}{$1.90(1.04-3.47)$} & \multirow{2}{*}{\multicolumn{2}{|c|}{$\begin{array}{l}2.02(1.01-4.04) \\
6.87(1.69-27.87)\end{array}$}} & \multirow{2}{*}{\multicolumn{2}{|c|}{$\begin{array}{l}1.70(1.02-2.84) \\
3.86(0.77-12.24)\end{array}$}} & \multicolumn{2}{|c|}{$2.68(1.03-6.96)$} \\
\hline$D M$ & 2.00 & $(0.33-11.99)$ & & & & & 1.09 & $(0.14-8.32)$ \\
\hline
\end{tabular}

Abbreviations, see text. 
A

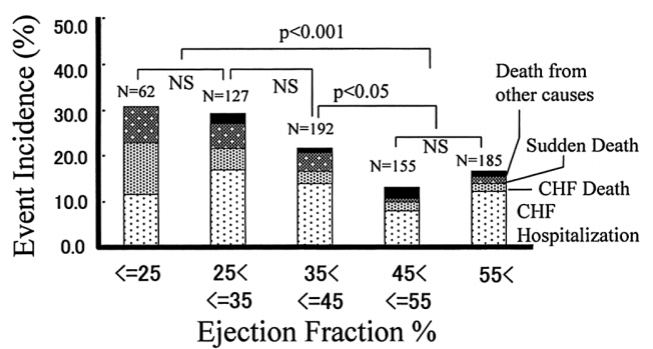

$\mathrm{B}$

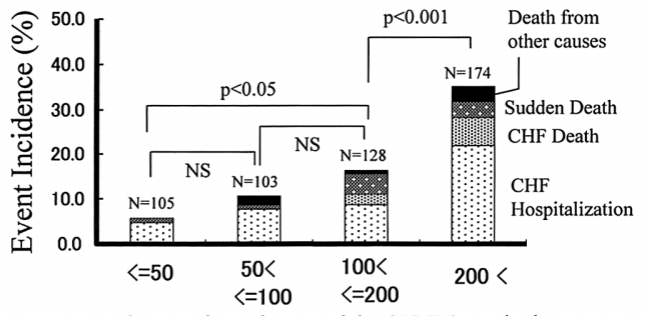

Brain natriuretic peptide (BNP) $\mathrm{pg} / \mathrm{ml}$

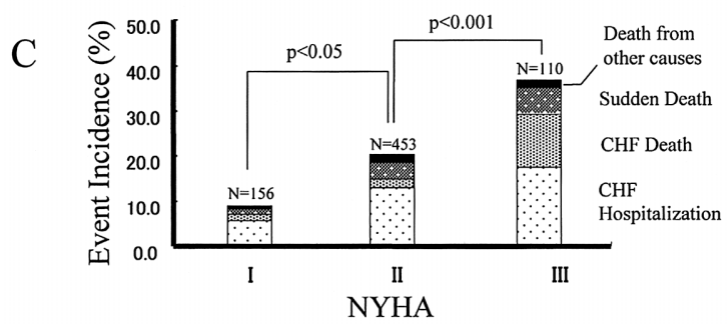

Fig 4. Summary of event-incidences for the various subgroups. CHF patients are categorized by EF (panel A), BNP (panel B) and NYHA (panel C). Event-incidence was significantly higher in patients with lower $\mathrm{EF}(\geq 45 \%)$ compared with patients with higher $\mathrm{EF}(>45 \%)$, but no further difference was found among patients whose EF was less than $45 \%$. Event-incidence was significantly higher in patients with high BNP $(>100 \mathrm{pg} / \mathrm{ml})$ compared to patients with low BNP $(\geq 50 \mathrm{pg} / \mathrm{ml})$, and it was significantly worse in patients with higher BNP $(>200 \mathrm{pg} / \mathrm{ml})$. Event-incidence was higher in patients with NYHA II than in those with NYHA I and lower in those with NYHA III. Abbreviations, see text.

rized by $\mathrm{EF}$ (panel $\mathrm{A}, \mathrm{n}=721$ ), $\mathrm{BNP}$ (panel $\mathrm{B}, \mathrm{n}=510$ ) and NYHA (panel C, $n=719$ ). The 1-year event incidence was higher in patients with $\mathrm{EF} \geq 45 \%(\mathrm{n}=381)$ than in patients with $\mathrm{EF}>45 \%(\mathrm{n}=340)$. The 1 -year crude mortality was $19 \%$ in patients with $\mathrm{EF} \geq 25 \%(\mathrm{n}=62), 13 \%$ in patients with $25<\mathrm{EF} \geq 35 \%(\mathrm{n}=127)$, and $8 \%$ in patients with $35<\mathrm{EF} \geq 45 \% \quad(\mathrm{n}=192)$, all of which were significantly higher $(p<0.001)$ than in patients with higher EF $>45 \%$ $(n=340,1$-year crude mortality 4-5\%). No significant difference in the 1-year event incidence was found among patients whose $\mathrm{EF}$ was less than $45 \%$. In panel $\mathrm{B}$, patients are categorized by BNP value. The 1-year event-incidence was higher in patients with BNP $>100 \mathrm{pg} / \mathrm{ml}(\mathrm{n}=302)$ than in patients with $\mathrm{BNP} \geq 50 \mathrm{pg} / \mathrm{ml}(\mathrm{n}=105)$. The event-incidence greatly increased in patients with BNP $>200 \mathrm{pg} / \mathrm{ml}$ $(\mathrm{n}=174)$. The 1-year crude mortality was $13 \%$ in patients with $\mathrm{BNP}>200 \mathrm{pg} / \mathrm{ml}(\mathrm{n}=174)$ and $8 \%$ in patients with $100<\mathrm{BNP} \geq 200 \mathrm{pg} / \mathrm{ml} \quad(\mathrm{n}=128)$, all of which were significantly higher than that in patients with BNP $\geq 100 \mathrm{pg} / \mathrm{ml}$ $\left(\mathrm{n}=208,1\right.$-year crude mortality $1-3 \%, \mathrm{p}<0.05$ by $\mathrm{X}^{2}$-test $)$. In panel $\mathrm{C}$, patients are categorized by NYHA grade. The 1-year event incidence was greater in patients with NYHA II $(n=453)$ than in patients with NYHA I $(n=156)$ and lower than in patients with NYHA III $(n=110)$. The 1-year crude mortality was $3.2 \%$ (2 HF death, 2 sudden death, 1 noncardiac death) in patients with NYHA I, 7.3\% (9 HF death, 16 sudden death, 8 non-cardiac death) in patients with NYHA II, and 19.1\% (13 HF death, 6 sudden death, 2 noncardiac death) in patients with NYHA III.

\section{Discussion}

It is important to characterize Japanese patients with CHF in order to design a future RCT and/or verify the outcome of evidence-based medicine. However, little data concerning the clinical characteristics and prognosis of CHF patients in Japan are available and in particular, the causes of death have not been systematically analyzed. This study is the first systematic report on the incidence of sudden death in Japanese CHF patients using more than 700 cases within a prospective setting.

\section{Etiologies of Japanese CHF Patients}

The present study highlights that VHD is the most frequent etiology for CHF patients overall, although the etiology of CHF differs according to age (Fig 1). In general, DCM is frequent in patients less than 59 years old, and VHD more frequent in patients more than 70 years old.

Itoh et $\mathrm{al}^{4}$ and Tsuchihashi et al ${ }^{5}$ reported that ischemic heart diseases were the most frequent etiology for CHF in Japan (32 and 35\%, respectively), but our data indicated that MI (ischemic) accounted for $23 \%$ of patients with CHF. The discrepancy may be caused by the definition of heart failure. Patients in the 2 previous studies experienced such severe congestive heart failure that they needed hospitalization, whereas the present study included patients with impaired LV function who did not experience clinical congestive heart failure; that is, these patients corresponded to Stage-B in the AHA/ACC treatment guideline for CHF? We included these Stage-B patients because they undoubtedly needed medical treatment to reduce or stop the progression of myocardial remodeling in order to prevent the progression of heart failure? The frequency of the etiologies should be further investigated with a nationwide survey using common criteria, as has been done for cardiomyopathies in Japan!

\section{Prognosis of Japanese CHF Patients}

The present study showed that the 1-year crude mortality was $8 \%$ in patients overall and worst in the MI groups (12\%); the LVH group showed the lowest mortality (4\%, $\mathrm{p}<0.05$ vs MI group). The 1-year crude mortality in the DCM group was $7 \%$. However, the 1-year incidence of clinical events, including death from any cause and HF hospitalization, was relatively high in both MI and LVH groups (Figs 2B, 3).

Tsuchihashi et $\mathrm{al}^{5}$ reported a 1-year crude mortality of $8.3 \%$ in their patients with heart failure and they reported that the crude mortality was worst in CHF with an ischemic etiology. The present study demonstrated nearly identical findings in terms of the crude mortality. Although they argued that Japanese CHF showed a relatively good prognosis compared with other Western countries, we think that it is difficult to make a simple comparison of mortality because the criteria of CHF, the background of the patients including age, underlying heart disease and co-morbidities were different. Philbin et al, based on a community-based study, reported that the majority of patients were female $(56 \%)$, and that the 6-month mortality was $23 \% !^{11}$ On the 
other hand, Mosterd et al reported a 1-year mortality of $11 \% ! 2$ In the present study, the 1-year mortality increased to $13-19 \%$ in the sub-group of patients with low cardiac function and/or high BNP (Fig 4). Also, the incidence of sudden death was nearly identical to that reported in previous large-scale clinical trials in Europe and the US6 Therefore, we believe that CHF in Japan and other Western countries has comparable severity when the heart failure progresses beyond a certain extent.

\section{Sudden Death in Japanese CHF Patients}

The present study showed a considerably high incidence of sudden death in Japanese CHF patients, particularly in the MI group, patients with low cardiac function, and patients with high concentrations of BNP. Surprisingly, $60 \%$ of deaths (11/19) occurred unexpectedly and suddenly in the MI group, and $40 \%$ of all deaths (24/59) were sudden.

Sudden death in the present study included non-cardiac causes such as cerebrovascular attack because all deaths were not always witnessed and/or received autopsy. Therefore, the present data may overestimate the incidence of sudden death from cardiac causes. The incidence of sudden death was relatively high in patients with MI (Fig 3) or with low cardiac function (Fig 4A), which coincides with the characteristics of the sudden cardiac death in previous reports. ${ }^{13}$

Based on the many RCT for CHF conducted in Europe and the US, it is recognized that sudden death in CHF is a serious problem, and it is believed that most cases are fatal ventricular arrhythmias6,14,15 Recently, MADIT-II confirmed this because the prophylactic use of an implantable cardioverter defibrillator in patients with MI and low EF was significantly effective 16 Although the mechanism of sudden death in Japanese CHF is not yet completely clear, we believe that fatal arrhythmias are closely related to the sudden death al least in patients with MI and/or poor cardiac function.

\section{Echocardiographic Measurements and BNP as Prognostic Markers}

The multivariate logistic regression analysis indicated that BNP was a consistent prognostic marker in CHF patients grouped according to different etiologies. The crude 1-year mortality was $2 \%$ (2 sudden death, 2 non-cardiac death) in 208 patients with $\mathrm{BNP} \geq 100 \mathrm{pg} / \mathrm{ml}$, and $11 \%$ (14 HF death, 12 sudden death, 7 non-cardiac death) in 302 patients with BNP $>100 \mathrm{pg} / \mathrm{ml}$. Overall, echocardiographic EF was a significant predictor for event-free survival in CHF patients, but not a consistent predictor in patients subgrouped according to the underlying heart disease. EF was a significant predictor for event-free survival in VHD patients and nearly significant in LVH patients. NYHA was not a consistent prognostic marker in etiologically grouped CHF patients.

Several investigators have reported that BNP is an independent prognostic factor for death by any cause, ${ }^{17}$ for cardiac events (cardiac death and HF hospitalization) ${ }^{18}$ and for sudden death ${ }^{19}$ in CHF patients. Troughton et al proposed that BNP-guided treatment of heart failure was superior to standardized clinical assessment-guided treatment ${ }^{20}$ and the present data clearly confirm those results (Fig 4B). We propose that a BNP of less than $100 \mathrm{pg} / \mathrm{ml}$ indicates a better prognosis in terms of the 1-year event incidence including all deaths and HF hospitalization.

Echocardiographic measurements are a widely accepted method for evaluating left ventricular function, but in some recent reports, multivariate analysis failed to show the efficacy of $\mathrm{EF}$ as a prognostic marker in patients with CHF!7-19,21 Our study also indicated that echocardiographic measurements have limited usefulness as a prognostic marker; that is, multivariate analysis demonstrated that $\mathrm{EF}$ is not a significant predictor of the 1-year mortality in patients with DCM, MI, or LVH. This may be at least partially caused by the relatively high incidence of cardiac events in CHF patients with preserved systolic function (Fig 4). Although it is unclear whether we can substitute BNP for echocardiographic measurements as prognostic marker, we tend to support BNP-guided treatment for CHF patients with the underlying heart diseases tested in this study. NYHA grading is a useful and well-accepted method of categorizing the severity of symptoms in heart failure patients, but it is a subjective assessment by an observer and changes frequently? Therefore, NYHA grading may have limited value as an objective prognostic maker.

\section{Study Limitations}

This was a multicenter prospective study to elucidate the characteristics and prognosis of currently treated CHF patients in the Tohoku district, Japan. We must acknowledge that some selection bias may have affected the present results, but to minimize the bias, we used objective criteria and encouraged the investigators to enroll patients who matched the criteria. We determined relatively loose criteria for the echocardiographic measurements (EF $\geq 50 \%$ or LVDD $\geq 55 \mathrm{~mm}$ ) to include patients with mild or potential heart failure because heart failure is a progressive disease, and it is important to determine the prognosis of such patients. Moreover, we included patients who had a past history of congestive heart failure even if the echocardiographic measurements were normal at the time of registration. These patients may have had not only systolic dysfunction but also diastolic dysfunction. So, careful interpretation is needed especially when we compare data with other studies. The management of CHF was not uniform especially in terms of drug therapy, partially because the guidelines for CHF treatment have not yet been widely disseminated. Therefore, we did not analyze the efficacy of evidencebased medicine (EBM) such as the application of angiotensin-converting enzyme inhibitors, angiotensin II receptor blockers and/or $\beta$-blockers in the present study. However, we used these drugs as covariate factors in the multivariate logistic regression analysis. Diabetes mellitus was a significant risk factor for the event-incidence in CHF patients with MI, but a detailed analysis was not performed. It is recognized that echocardiographic measurements may have some error especially in patients with previous MI; however, they are an accepted method for the assessment of LV function in RCT, which have included post MI patients. ${ }^{1-3}$

The total number of patients may not have been adequate for analysis in the particular subgroups; for example, we did not analyze patients with CHD and other unclassified heart diseases because the numbers of cases were too small.

In summary, the present study determined the most frequent etiology for CHF in younger patients in Japan to be DCM and VHD in older patients. The overall 1-year crude mortality was $8 \%$, and it was worst in patients with MI (12\%). Sudden death accounted for $40 \%$ of all deaths. BNP appears to be an excellent prognostic marker for clinical events including HF death, sudden death, and HF hospitalization in Japanese patients with CHF. 
In conclusion, the etiologies of Japanese CHF were more diverse than those of other Western countries, but BNP is an excellent prognostic marker despite this diversity. Sudden death is also a common outcome for Japanese CHF patients. We need a larger epidemiologic study to characterize Japanese $\mathrm{CHF}$ in order to construct a $\mathrm{RCT}$ and/or to verify the outcome of the current EBM in the real clinical situation.

\section{Acknowledgments}

Active investigators of the Chronic Heart Failure Analysis Registry in Tohoku District (CHART): Dr J Kikuchi, Dr S Oyama (Towada City Central Hospital); Dr K Tamaki, Dr E Nozaki, Dr H Hozawa, Dr Y Yamamoto, Dr T Nozaki, Dr S Suzuki (Iwate Prefecture Central Hospital); Dr Y Onodera, Dr M Nakagawa (Iwate Prefecture Isawa Hospital); Dr N Hoshi, Dr A Nakamura (Miyako Prefectural Hospital); $\mathrm{Dr} S$ Sato, $\mathrm{Dr} H$ Kinoshita, Dr M Funakoshi (Kamaishi shimin Hospital); Dr M Hayashi, Dr H Watanabe, Dr N Sekiguchi, Dr M Takeuchi (Hiraka General Hospital); Dr Y Onodera, Dr M Chida (Ogachi Central Hospital); Dr M Ohe, $\operatorname{Dr} M$ Komatu (Koshirakawa Shiseidou Hospital); Dr M Sugi, Dr S Namiuchi (Iwaki Kyouritu Hospital); Dr N Uesugi (Nikkou Kinen Hospital); Dr Y Sekiguchi (Watanabe Hospital); Dr N Shiba. Dr S Horiguchi, Dr H Shioiri (Katta General Hospital); Dr S Kitaoka, Dr H Kyono, Dr K Inoue., Dr K Sakurai, Dr T Watanabe (Sendai National Hospital); Dr M Kanazawa, Dr A Kato, Dr A Sugimura, Dr T Tanikawa, Dr M Funakoshi (Sendai Open Hospital Sendai City Medical Center); Dr T Mimata (Rifu Ekisaikai Hospital); Dr N Ishide, Dr H Oda (Sendai Tokushukai Hospital); Dr T Hiramoto (Tohoku Kosai Hospital); Dr T Nunokawa, Dr N Itoh (Labour Welfare Corporation Tohoku Rosai Hospital); Dr M Kuroha (JR Sendai Hospital).

This study was supported by the research grant for cardiovascular diseases (14-1) from the Ministry of Health, Labor and Welfare, and Gonryo Medical Foundation (2000-B). We greatly thank Ms Hiroko Miura for her excellent secretary skills, and Mr Brent Bell for reading manuscript.

\section{References}

1. The CONSENSUS Trial Study Group. Effects of enalapril on mortality in severe congestive heart failure: Results of the Cooperative North Scandinavian Enalapril Survival Study (CONSENSUS). $N$ Engl J Med 1987; 316: 1429-1435.

2. CIBIS-II investigators. The Cardiac Insufficiency Bisoprolol Study II (CIBIS-II): A randomized trial. Lancet 1999 353: 9-13.

3. Cohn JN, Tognoni G. A randomized trial of the angiotensin-receptor blocker valsartan in chronic heart failure. $N$ Engl J Med 2001; 345: $1667-1675$.

4. Itoh A, Saito M, Haze K, Hiramori K, Kasagi F. Prognosis of patients with congestive heart failure: Its determinants in various heart diseases in Japan. Intern Med 1992; 31: 304-309.

5. Tsuchihashi M, Tsutsui H, Kodama K, Kasagi F, Takeshita A. Clinical characteristics and prognosis of hospitalized patients with congestive heart failure: A study in Fukuoka, Japan. Jpn Circ J 2000; 64: $953-959$

6. Stevenson WG, Sweeney MO. Arrhythmias and sudden death in heart failure. Jpn Circ J 1997; 61: 727-740.

7. Huikuri HV, Castellanos A, Myerburg RJ. Sudden death due to cardiac arrhythmias. N Engl J Med 2001; 345: 1473-1482.

8. Hunt SA, Baker DW, Chin MH, Cinquegrani MP, Feldman AM, Francis GS, et al. ACC/AHA guidelines for the evaluation and management of chronic heart failure in the adult: Executive summary: A report of the American College of Cardiology/American Heart Association Task Force on Practice Guidelines (Committee to revise the 1995 Guidelines for the Evaluation and Management of Heart Failure). J Am Coll Cardiol 2001; 38: 2101-2113.

9. Cohn JN, Ferrari R, Sharpe N. Cardiac remodeling: Concepts and clinical implications: A consensus paper from an international forum on cardiac remodeling. Behalf of an International Forum on Cardiac Remodeling. J Am Coll Cardiol 2000; 35: 569-582.

10. Matsumori A, Furukawa Y, Hasegawa K, Sato Y, Nakagawa H, Morikawa Y, et al. Epidemiologic and clinical characteristics of cardiomyopathies in Japan: Results from nationwide surveys. Circ J 2002; 66: 323-336.

11. Philbin EF, Rocco TA Jr, Lindenmuth NW, Ulrich K, Jenkins PL. Clinical outcomes in heart failure: Report from a community hospitalbased registry. Am J Med 1999; 107: 549-555.

12. Mosterd A, Cost B, Hoes AW, de Bruijne MC, Deckers JW, Hofman $\mathrm{A}$, et al. The prognosis of heart failure in the general population: The Rotterdam Study. Eur Heart J 2001; 22: 1318-1327.

13. Myerburg RJ, Mitrani R, Interian A Jr, Castellanos A. Interpretation of outcomes of antiarrhythmic clinical trials: Design futures and population impact. Circulation 1998; 97: 1514-1521.

14. Luna AB, Coumel P, Leclercq JF. Ambulatory sudden cardiac death: Mechanisms of production of fatal arrhythmia on the basis of data from 157 cases. Am Heart J 1989; 117: 151 - 159.

15. Tomaselli GF, Beuckelmann DJ, Calkins HG, Berger RD, Kessler $\mathrm{PD}$, Lawrence JH, et al. Sudden cardiac death in heart failure: The role of abnormal repolarization. Circulation 1994; 90: 2534-2539.

16. Moss AJ, Zareba W, Hall WJ, Klein H, Wilber DJ, Cannom DS, et al. Prophylactic implantation of a defibrillator in patients with myocardial infarction and reduced ejection fraction. N Engl J Med 2002; 346: $877-883$.

17. Bettencourt P, Ferreira A, Dias P, Pimenta J, Frioes F, Martins L, et al. Predictors of prognosis in patients with stable mild to moderate heart failure. J Card Fail 2000; 6: 306-313.

18. Imamura $Y$, Fukuyama T, Mochizuki T, Miyagawa M, Watanabe K. Prognostic value of iodine-123-metaiodobenzylguanidine imaging and cardiac natriuretic peptide levels in patients with left ventricular dysfunction resulting from cardiomyopathy. Jpn Circ J 2001; 65: $155-160$.

19. Berger R, Huelsman M, Strecker K, Bojic A, Moser P, Stanek B, et al. B-type natriuretic peptide predicts sudden death in patients with chronic heart failure. Circulation 2002; 105: 2392-2397.

20. Troughton RW, Frampton CM, Yandle TG, Espiner EA, Nicholls MG, Richards AM. Treatment of heart failure guided by plasma aminoterminal brain natriuretic peptide (N-BNP) concentrations. Lancet 2000; 355: 1126-1130.

21. Maeda K, Tsutamoto T, Wada A, Mabuchi N, Hayashi M, Tsutsui T, et al. High levels of plasma brain natriuretic peptide and interleukin6 after optimized treatment for heart failure are independent risk factors for morbidity and mortality in patients with congestive heart failure. J Am Coll Cardiol 2000; 36: 1587-1593. 